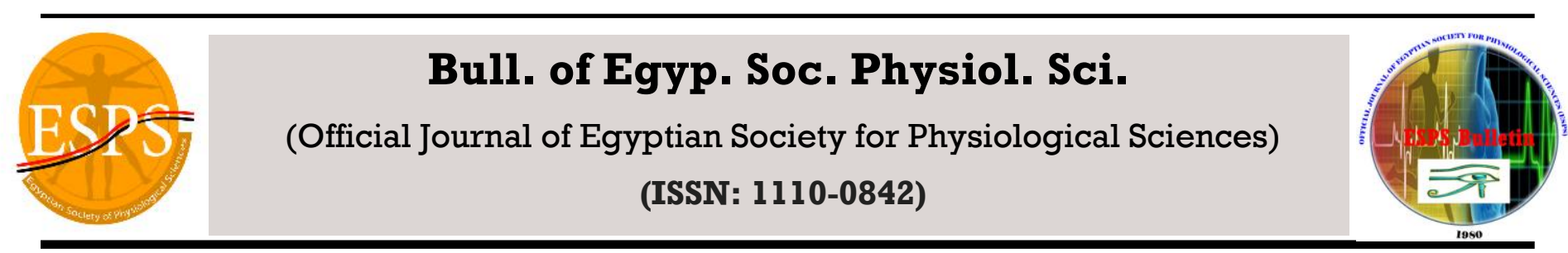

\title{
Effect of Moderate and Severe Swimming Exercise on Hepatic Injury and Apoptosis Induced by Renal Ischemia Reperfusion in Male Albino Rats
}

Received: June 19, 2014 Accepted: Sept 28, 2104 Available online: Oct 30, 2014

\section{Keywords}

- Ischemia reperfusion

- Swimming

- Exercise

- Malondialdehyde

- Caspase-3.

, 201

\author{
Mervat H. El-Saka, Nermin M. Madi, Ghada M. Abou Fard \\ Physiology Department, Faculty of Medicine, Tanta University
}

\begin{abstract}
Objective: to investigate the effects of moderate and severe exercise on hepatic injury induced by renal ischemia reperfusion (IR) in male albino rats. Methods: 40 male albino rats were divided into 4 groups (10 rats each): sedentary sham-operated-control, sedentary renal IR group, moderate exercise-IR group and severe exercise-IR group. In the last two groups, swimming exercise protocol performed for 6 weeks, then rats were subjected to renal IR. At the end of experiment, serum levels of alanine aminotransferase (ALT) and aspartate aminotransferase (AST) and liver levels of malondialdehyde (MDA), superoxide dismutase (SOD), reduced glutathione (GSH), catalase (CAT), caspase-3 activity and TNF- $\alpha$ were assessed. Results: renal IR caused nonsignificant increase in the levels of ALT and AST with significant increase in hepatic MDA and TNF- $\alpha$ levels, while SOD and GSH levels showed significant decrease. CAT and caspase-3 showed insignificant change in IR group compared to sham group. Moderate exercise prior to renal IR showed insignificant decrease in ALT and AST levels, significant decrease in hepatic MDA and TNF- $\alpha$ levels, significant increase in hepatic SOD, GSH and CAT and non-significant change in caspase-3 compared to renal IR sedentary group. On the other hand, severe exercise prior to renal IR showed significant increase in ALT and AST levels, also hepatic MDA and TNF- $\alpha$ levels were significantly increased, while, hepatic SOD and GSH levels significantly decreased as compared to renal IR sedentary group, CAT levels insignificantly increased as compared to renal IR sedentary group. Caspase-3 insignificantly increased as compared to renal IR sedentary group but showed significant increase when compared to sham control group. Conclusions: Moderate exercise swimming ameliorates hepatic injury induced by renal IR by its antioxidant and anti-inflammatory effects. While, severe exercise deteriorates the hepatic injury induced by renal IR by increasing the oxidative stress.
\end{abstract}

Corresponding author: Mervat H. El-SakaSaka, Medical Physiology Department, Faculty of Medicine, Tanta University, Tanta, Egypt. E-mail: tantaphysiology@yahoo.com: Mob.: 01023126578 


\section{INTRODUCTION}

Liver and kidney are important regulators of body homeostasis and are involved in excreting the toxic products of metabolism and exogenous drugs (1). Any injury to either the renal or liver tissue may affect the other (2).

Reactive oxygen species (ROS) and nitric oxide (NO) play an important role in mediating cell damage during ischemia reperfusion (IR) injury(3). Inflammation contributes to the pathogenesis of IR with a central role for particular cells, adhesion molecules, and cytokines (4). Neutrophils are the inflammatory cells, which produces abundantly ROS during IR injury (5).

Renal IR causes tissue injury by oxygen radicals and oxidative stress caused by an imbalance between production of ROS and antioxidant capacity $(6,7)$.

Liver injury is one of the distant-organ damages induced by renal IR. Acute renal failure associated with liver disease is a commonly encountered clinical problem of varied etiology (8). It is believed that IR injury induces inflammatory response, which elicits tissue damage in a number of organs in which reactive oxygen and nitrogen species play a key role in the pathophysiology of tissue injury $(9,10)$. It has been demonstrated that renal IR injury might cause liver oxidative stress and increase lipid peroxidation in liver tissue (11).

Apoptosis is a physiological, highly organized and genetically programmed form of cell death which contributes to body homeostasis by removing aged and damaged cells(12). Thus, apoptosis represents a protective defense mechanism against a number of harmful factors including viral attacks and carcinogens (13). However, aberrant hepatocyte apoptosis may induce hepatic injury and disease progression via up-regulation of inflammation and fibrosis (14).

Exercise training has various effects on hepatic function (15). In rats, training modulates antioxidant enzymes in the liver, reducing oxidative damage (16). Regular physical activity reduces the risk of cardiovascular disorders, diabetes, obesity, cancer and premature death (17). However, the beneficial effects of physical activity are lost with exhaustion (18). Severe exercise training represents a physical stress that disrupts homeostasis (19), and the working skeletal muscle is clearly the organ most directly affected during physical activity (20).

Previous studies indicate that exercise may induce structural damage to muscle cells (21), and the production of metabolic by-products, such as lactate (22), and ROS (23). The metabolic adaptations to exercise are not restricted to the working muscles, exercise also a major challenge to other organs such as cardiac muscle, stomach or brain (24). This is particularly relevant to the liver due to its central role in the maintenance of energy supply to the exercising muscle (25).

Although, there were numerous previous studies aiming to evaluate the effects of exercise on liver functions and oxidative stress in liver, but there has been no study of the effect of moderate and severe exercise on liver injury induced by renal IR. So, this study designed to investigate the effects of moderate and severe swimming exercise on hepatic injury and apoptosis induced by renal IR in male albino rats 


\section{MATERIALS AND METHODS}

\section{Animals:}

This study was carried out on 40 male albino rats weighing about (200-250gm) were housed under standard laboratory conditions at room temperature $\left(24 \pm 2^{\circ} \mathrm{C}\right)$. The rats had free access to water and food.

\section{Experimental design:}

Rats were divided into four groups (10rats each): Sedentary sham-operated-control: rats in this group were subjected to sham operation; Sedentary renal IR group; rats in this group were subjected to renal IR; Moderate exercise-IR group: rats in this group performed moderate swimming exercise for 6 weeks, then were subjected to renal IR; severe exercise-IR group: rats in this group performed severe swimming exercise for 6 weeks, then they were subjected to renal IR.

\section{Induction of renal IR injury:}

According to Vaghasiya et al.,(1), the I/R to the kidneys was induced. Rats were anaesthetized with pentobarbital $(40 \mathrm{mg} / \mathrm{kg})$ intraperitoneally. The abdominal region was shaved and sterilized. Rats were undergoing surgical exposure of the left and right renal pedicles via midline incision. To induce renal ischemia, both renal pedicles were occluded for 30 minutes with vascular clamps. After $30 \mathrm{~min}$. of occlusion, the clamps were removed, and kidneys observed to undergo reperfusion for 24 hours. Sham-operated animals underwent identical surgical treatment, however, without occlusion of the renal pedicles.

\section{Swimming exercise protocol:}

Moderate swimming exercise protocol: the swimming exercise protocol was conducted 5 times/week for $60 \mathrm{~min} /$ time for 6 weeks. The rats swam individually in water tank. The tank used in this study $80 \mathrm{~cm}$ in length, $50 \mathrm{~cm}$ in width and $90 \mathrm{~cm}$ in depth, and the swimming training was always performed in water temperature of $31 \pm 1^{\circ} \mathrm{C}$, between 10 to $12 \mathrm{~h}$ a.m.(26).

Severe swimming exercise protocol: The exercise regimen for severe exercise-trained rats, the same as for moderate exercise-trained rats but to augment the exercise intensity, an external load was added to the animal; the animal carried a load of $50 \%$ body weight strapped to the chest in the second week. In the third and fourth training weeks, the animals performed the same exercise carrying a load of $60 \%$ body weight, and in the last two weeks, this load increased to $70 \%$ of body weight (27).

\section{Biochemical assays:}

At the end of experiment, rats were sacrificed and blood samples were collected for biochemical assays, and livers were quickly removed and kept frozen until assayed for oxidant and antioxidant parameters.

The following parameters were determined:

\section{Liver function assay:}

Serum alanine aminotransferase (ALT) and aspartate aminotransferase (AST) were measured according to the method of Rei(28) .

Estimation of lipid peroxidation and antioxidant enzymes:

Liver was removed and kept in cold conditions until assayed. The tissue was homogenized, the clear supernatant was used for assays of lipid peroxidation (MDA content) according to Esterbauer and Cheeseman(29), superoxide dismutase (SOD) according to Marklund and Marklund (30), catalase (CAT) that determined by Aebi(31) and reduced glutathione (GSH) according to Nagi et al., (32) 


\section{Estimation of caspase-3 activity and TNF- $\alpha$ :}

Caspase-3 was measured by ELISA method according to(33), and TNF- $\alpha$ was determined by

Endo et al., (34)

\section{Statistical analysis:}

The data were expressed as the mean \pm standard deviation. Data from our study were analyzed using the unpaired student's t-test to assess significant difference between two groups.

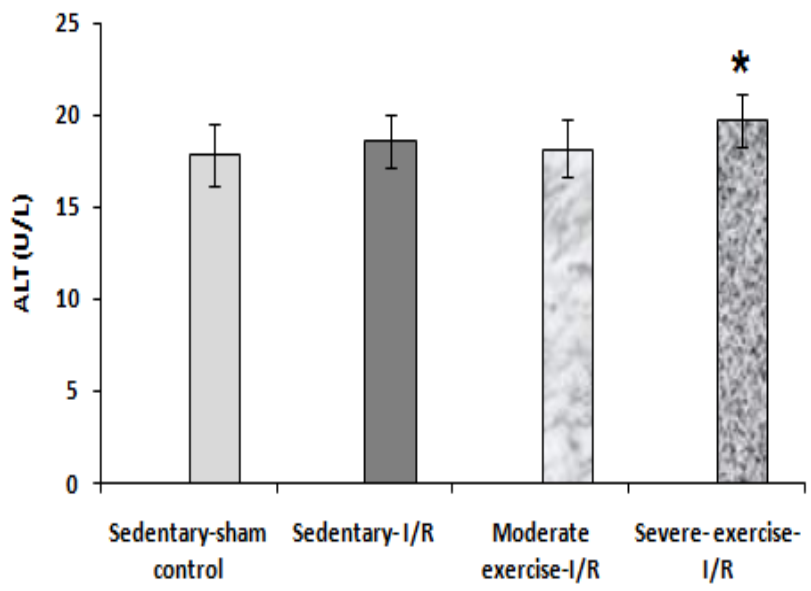

Statistical comparison between different groups was carried out by using one-way ANOVA. Significant results of analysis of variance were subjected to post hoc analysis (Tukey-Kramer multiple comparisons). P-values $<0.05$ were considered statistically significant. All the analyses were performed using Graph Pad Instat, 32 bit for win 95/NT (Version 3.05).

Figure (1): Effect of moderate and severe exercise on liver function after induction of renal $\mathrm{I} / \mathrm{R}$ injury in rats. ${ }^{\text {* }} \mathrm{P}<0.05$ vs sham-operated control group. ${ }^{\#} \mathrm{P}<0.05$ vs renal $\mathrm{I} / \mathrm{R}$ group. ${ }^{\$} \mathrm{P}<0.05$ vs moderate exercise-I/R group.

\section{Statistical analysis:}

The data were tabulated and analyzed by SPSS (statistical package for the social science software) using statistical package version 16 on IBM compatible computer. Quantitative data were expressed as mean \pm standard deviation $(\mathrm{X} \pm \mathrm{SD})$. The data from control and test groups were compared using an independent sample t-test. Probability value of less than 0.05 was considered as statistically significant $(* \mathrm{P}<0.05)$. " $\mathrm{n}$ " indicates the number of tested rats.

\section{RESULTS}

Effect of muscle exercise on liver function in renal IR

As shown in table fig. (1), serum levels of ALT and AST were insignificantly increased in IR

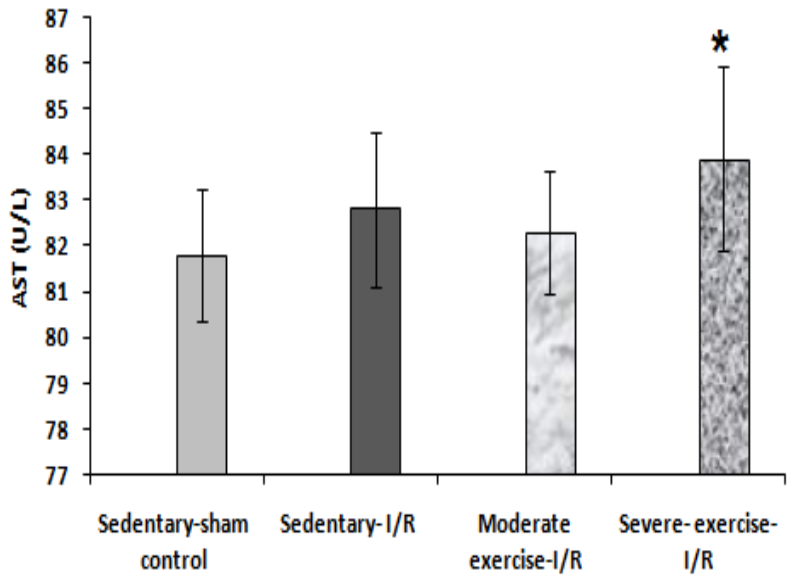

group as compared to the sham-operated control group (P> 0.05). Rats underwent moderate exercise prior to renal IR were exhibited insignificant decrease in the serum levels of ALT and AST as compared renal IR group and exhibited no significant change as compared to sham-operated group. While, rats that underwent severe exercise prior to renal IR showed insignificant change in serum levels of ALT and AST as compared to renal rats in sedentary IR group, but showed significant increase when compared to the sham-operated control group.

\section{Effect of muscle exercise on lipid peroxidation} and antioxidant enzymes in renal IR

Compared with sham-operated control group, liver MDA levels were significantly increased, while 
SOD and GSH levels were significantly decreased in IR group $(\mathrm{P}<0.05)$. But, CAT levels insignificantly changed in IR group as compared to sham group fig. (2).

The MDA levels in liver tissue, was significantly decreased in rats that underwent moderate exercise prior to renal IR compared to rats in the sedentary
IR group $(\mathrm{P}<0.05)$, but insignificantly changed as compared to sham-operated control group. While, rats that underwent severe exercise prior to renal IR were exhibited significant increase in the MDA levels compared to rats in the sedentary IR group, rats in sham-operated control group and rats in the moderate exercise IR group fig. (2).
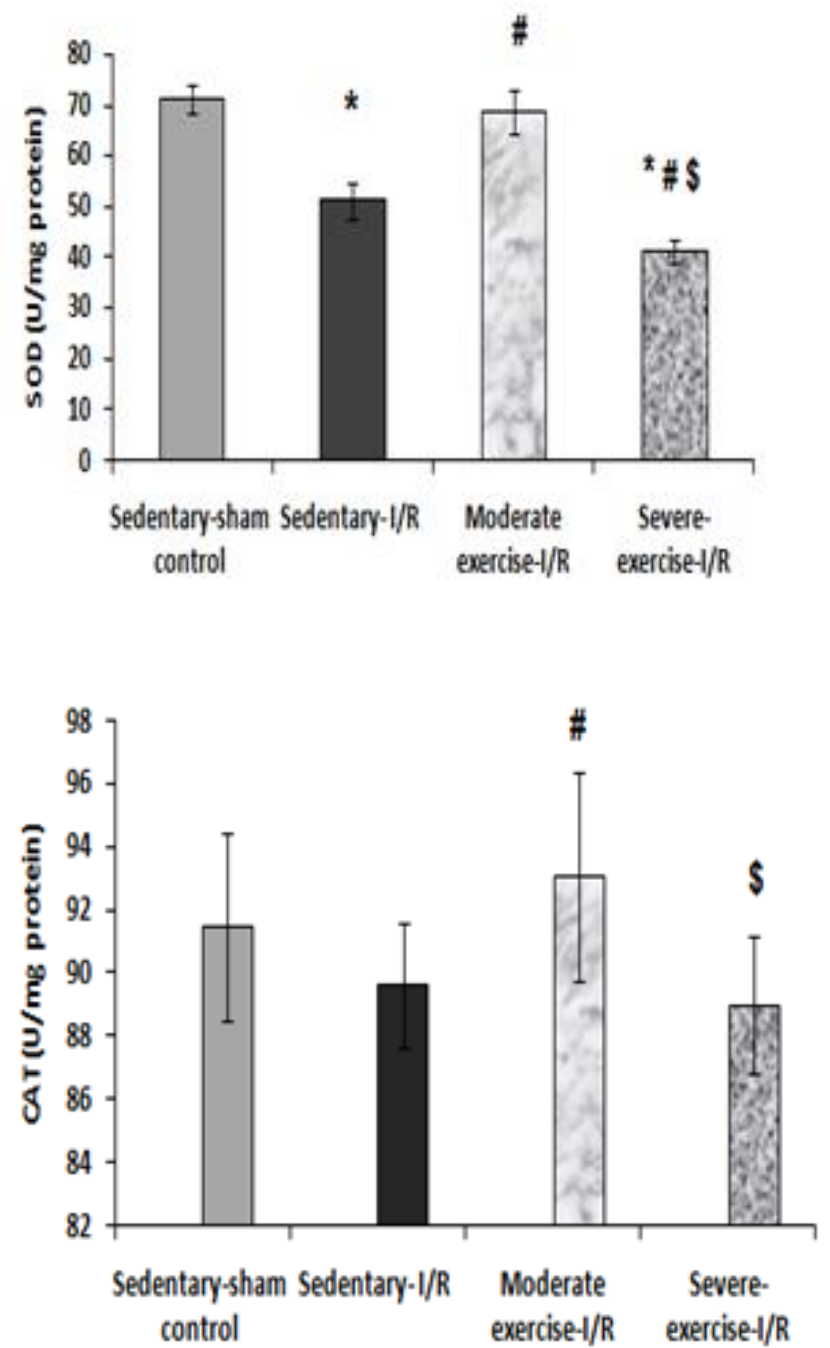

Figure (2): Effect of moderate and severe exercise on lipid peroxidation and antioxidant enzymes in the liver after induction of renal $\mathrm{I} / \mathrm{R}$ injury in rats. $* \mathrm{P}<0.05$ vs sham-operated control group. $\# \mathrm{P}<0.05$ vs renal $\mathrm{I} / \mathrm{R}$ group. $\$ \mathrm{P}<0.05 \mathrm{vs}$ moderate exercise-I/R group

As regard SOD and GSH levels, both are significantly increased in rats underwent moderate exercise prior to IR as compared to the rats in the sedentary IR group, but they showed no significant difference if compared to the sham-operated control group. While, severe exercise prior to IR significantly decreased the levels of SOD and GSH as compared to rats in the sedentary IR 
Table (1): Effect of moderate and severe exercise on caspase 3 activity and TNF- $\alpha$ in the liver after induction of renal I/R injury in rats

\begin{tabular}{|l|c|c|c|c|}
\hline \multicolumn{1}{|c|}{ Parameters } & $\begin{array}{c}\text { Group I } \\
\text { Sedentary-sham } \\
\text { control } \\
(\mathbf{n = 1 0})\end{array}$ & $\begin{array}{c}\text { Group II } \\
\text { Sedentary- I/R } \\
(\mathbf{n}=\mathbf{1 0})\end{array}$ & $\begin{array}{c}\text { Group III } \\
\text { Moderate } \\
\text { exercise-I/R } \\
(\mathbf{n = 1 0})\end{array}$ & $\begin{array}{c}\text { Group IV } \\
\text { Severe- } \\
\text { exercise-I/R } \\
(\mathbf{n = 1 0})\end{array}$ \\
\hline $\begin{array}{l}\text { Caspase 3 activity (nmol } \\
\text { /mg protein) }\end{array}$ & $1.06 \pm 0.32$ & $1.36 \pm 0.46$ & $1.18 \pm 0.36$ & $1.86 \pm 0.77^{\mathrm{a}, \mathrm{c}}$ \\
\hline TNF- $\boldsymbol{\alpha}$ (pg/mg protein) & $13.83 \pm 0.77$ & $22.53 \pm 1.72^{\mathrm{a}}$ & $15.15 \pm 1.81^{\mathrm{b}}$ & $26.30 \pm 1.39^{\mathrm{a}, \mathrm{b}, \mathrm{c}}$ \\
\hline
\end{tabular}

Data are given as mean \pm SD. aP $<0.05$ vs sham-operated control group. bP $<0.05$ vs renal I/R group. $\mathrm{cP}<0.05$ vs moderate exercise-I/R group

group, rats in sham-operated control group and rats in the moderate exercise IR group fig. (2).

Moderate exercised IR group showed a significant increase in CAT activity levels as compared to the sedentary IR group and

\section{Effect of muscle exercise on caspase-3 activity} and TNF- $\alpha$ in renal IR:

Table (1) showed that caspase-3 was insignificantly increased in IR group as compared to sham-operated control rats $(\mathrm{P}>0.05)$. While, TNF- $\alpha$ was significantly increased in IR group in comparison with sham-operated group $(\mathrm{P}<0.05)$.

Table (1) showed that caspase-3 levels were insignificantly decreased in moderate exercised IR rats as compared to sedentary IR rats $(\mathrm{P}>0.05)$, and insignificantly changed as compared to shamoperated control group. While, in the severe exercised group, there were insignificant increase in caspase-3 levels as compared to sedentary IR group. But, the increase became significant if compared to both the sham-operated rats and to the rats in the moderate exercise IR group. insignificant increase as compared to shamoperated group. But, in the severe exercised group, CAT activity levels were insignificantly changed compared to both the sedentary IR group and sham-operated group, and showed significant decrease if compared to the moderate exercise IR group.

TNF- $\alpha$ levels were significantly decreased in rats that underwent moderate exercise prior to renal IR group compared to rats in sedentary IR group $(\mathrm{P}<0.05)$ but, they showed no significant difference if compared to the sham-operated control group. While, rats that underwent severe exercise prior to renal IR were exhibited significant increase in the levels of TNF- $\alpha$ as compared to rats in the sedentary IR group, rats in sham-operated control group and rats in the moderate exercise IR group (table 1).

\section{DISCUSSION}

Renal IR injury is encountered in many clinical situations; transplantation, partial nephrectomy, sepsis, hydronephrosis, or elective urologic operations (35). At present, many studies have shown remote organ injury, including the liver, during renal IR(36). 
The liver plays a role in the physiology of exercise (16). Exercise has various effects on liver function, enhancing both nutrient metabolism and antioxidant capacity (37).

The effect of exercise on health is paradoxical, because the formation of ROS induced by exercise may be detrimental for cellular functions (38). Strenuous exercise was shown to increase ROS mediated lipid peroxidation in the liver (39), skeletal muscle (40), myocardium (41), and lung tissue(42). On the other hand, exercise, while enhancing the generation of ROS, was suggested to activate the defense mechanisms that protect against detrimental effects associated with ROS (43).

The present study demonstrated that renal IR leads to damage to the liver as remote organ. Our findings suggested that moderate exercise attenuates IR-induced liver functional injury, while severe exercise deteriorates the IR-induced liver functional injury.

The present study showed that serum ALT and AST levels insignificantly increased after induction of renal IR as compared to sham control. But, we found significant higher MDA levels in the liver tissue after induction of renal IR injury as compared to sham-control, which is a major index of lipid peroxidation and oxidative stress. In the present study, renal IR leads to decreased levels of antioxidant enzymes in the liver tissue including GSH and SOD as compared to sham control, while CAT level insignificantly changed as compared to sham group. Also, the present work showed that 30 min-renal ischemia, 24 hours reperfusion was enough to significantly increase TNF- $\alpha$ level in the liver as compared to those levels observed in the sham-control, while caspase-3 levels were insignificantly increased as compared to shamcontrol.

Several mechanisms are suggested to be involved in remote organ failure, but their exact pathophysiological roles are not completely understood $(9,10)$. Chemokines and mitochondrial products activate neutophils to amplify remote liver injury during mouse acute renal failure (44). Renal IR results in uncontrolled expression of interleukin-17A(45). IL-17A is a proinflammatory cytokine that causes recruiting neutrophils, activate $\mathrm{T}$ cells, and induces expression of other cytokines and chemokines such as TNF- $\alpha$ and IL-6 in liver tissue(46). It has been shown that TNF- $\alpha$ play an important role in early IR injury (44).

TNF- $\alpha$ is a pro-inflammatory cytokine mainly produced from macrophages and monocytes and in the liver from Kupffer cells(47). It acts locally in a paracrine fashion but also at distant sites in the manner of hormones(44). Seteser et al(48), showed that renal IR increased the hepatic levels of TNF$\alpha$. Increased oxidative stress and production of ROS in the liver that were shown in the present study are also thought to play a key role in triggering and maintaining the inflammatory response. MDA, an index of lipid peroxidation, was found to be increased in the liver after renal IR(49). In addition, hepatic glutathione, an important endogenous free radical scavenger with protective effects on the liver, was decreased(8). Administration of glutathione before renal IR decreased histological evidence of liver injury and MDA concentrations (8).

The results of the present work demonstrated that moderate exercise for 6 weeks prior to renal IR insignificantly affect serum ALT and AST levels, 
but caused significant decrease in MDA in liver tissue as compared to rats in sedentary renal IR group, antioxidant enzymes like SOD, GSH and CAT were significantly increased in the liver tissue in moderate exercised-IR group compared to sedentary IR group. Also, TNF- $\alpha$ levels were significantly decreased in moderately-exercised IR group, while caspase-3 level insignificantly changed as compared to sedentary IR group.

In accordance to the results of the present work, Cakir et al.,(40) demonstrated that stress induced oxidative damage in the cardiac muscle, liver, stomach, and brain of sedentary rats that assessed by increased MDA levels, is ameliorated when the animals have previously swum at a moderate load for 8 weeks.

It has been hypothesized that moderate regular exercise can be beneficial by up-regulating the protective activities against oxidative stress (50). Radak et al.,(51) showed that regular exercise attenuated the increased redox status, evaluated by glutathione level that showed more than a two-fold increase in GSH in exercised rats.

The protective effect of exercise against stressinduced oxidative damage of remote organs appears to involve the maintenance of GSH stores and an inhibitory action on tissue neutrophil recruitment, alleviating neutrophil-derived oxidative injury (23)

In accordance to the results of the present work, some studies have shown that animals and humans clearly undergo significant adaptive responses to regular exercise which is permitted by reduction in oxidant production and increased antioxidant defenses $(19,52)$. In this context, the liver plays a key role in stress-induced oxidative injury (53).
For instance, liver is the major organ for de novo GSH synthesis, supplying $90 \%$ of the circulating GSH, which is one of the most important endogenous antioxidants(54) and plays an important role as a reducing agent(53) protecting the organism against hydrogen peroxide and lipid peroxides(52). Sun et al.,(53) found increased liver mitochondria GSH after 4 weeks of training exercise in rats, which was attributed to an increased antioxidant activity. Navarro et al.,(43) also reported that chronic moderate exercise increases mitochondrial SOD activity and decreased mitochondrial oxidation products in trained rat liver. In agreement to this view, Botezelli et al.,(55) have demonstrated that 8 weeks of swimming training decreased lipid peroxidation, a fact partially attributed to an improved antioxidant system with greater SOD enzyme activity.

The previous reports found no significant difference between tissue and isolated mitochondria measurements (53). Thus, no difference between GSH and MDA in tissue homogenate and isolated mitochondria have been observed following exercise training in $\operatorname{rat}(24)$.

Radak et al.,(56) investigated the activity of nuclear factor-kB (NF-kB) which is an important redox sensitive transcription factor that regulates various inflammatory and immune responses. The binding activity of NF-kB in nuclear extracts to deoxyoligonucleotide with the responsive element reduced with the exercise regimen suggesting that regular exercise may attenuate the inflammatory processes (57).

Additionally, it is interesting to note that proteins in cardiac muscles of rats subjected to regular swimming training for 9 weeks were more 
resistant to an oxidative challenge of intraperitoneal injection of $\mathrm{H} 2 \mathrm{O} 2(57)$. Regular exercise increases antioxidant enzyme activities in rat skeletal muscles (18) and the liver (58), taken together, these results support the results of the present work that moderate exercise up-regulates protection against oxidative stress.

Concerning antioxidant effects of exercise, a substantial body of evidence suggests that regular exercise plays an important preventive and therapeutic role in oxidative stress-associated diseases including ischemic heart disease (59), type II diabetes (60), and Alzheimer disease (61).

The mechanism by which moderate exercise training exerts its anti-inflammatory effects has been largely focused on the effects of reduced adiposity and reduced release of adipose tissuederived inflammatory cytokines (62). Adipose tissue is recognized as a metabolically active tissue that plays a key role in the development of chronic low-grade inflammation (63). Adipose tissue is able to produce inflammatory cytokines such as TNF- $\alpha$ and IL-6 and several potent chemoattractant cytokines (62). The accumulation of monocytes as macrophages in adipose tissue is thought to be a major source of increased systemic concentrations of inflammatory cytokines (64). With this in mind, increased physical activity that results in a negative energy balance and consequently reduces adiposity, have been typically suggested as the main mechanism by which regular exercise exerts its beneficial effects on the level of inflammatory markers(65).

The results of the present work showed that severe exercise-prior to the renal IR deteriorates the liver injury caused by renal IR manifested by significant increase in serum ALT and AST and hepatic
MDA levels as compared to sedentary IR group, while, significant decrease of hepatic SOD and GSH as compared to sedentary IR group, but, CAT level insignificantly changed as compared to sedentary IR group and TNF- $\alpha$ in liver tissue showed significant increase as compared to sedentary IR group, while, caspase-3 insignificantly increased as compared to sedentary IR group and showed significant increase when compared to sham control group.

It is well known that exhaustion caused by exercise, especially when it occurs sporadically, leads to structural damage or inflammatory reactions within the muscles (41). This damage is due to, at least in part, to the production of ROS (66). Also, it was reported that ROS production by acute or chronic exercise may elicit different responses depending on the type of organ tissue and its levels of endogenous antioxidants (67). Severe exercise by increasing the oxygen consumption rate may result in oxidative stress in mitochondria. This results in an increased production of oxidants, which could be detrimental to the tissue (23). The liver is the organ situated at the border between the digestive and circulatory systems and their functions are not bound only by digestion (68). At level of the liver many biochemical cycles occur and they can result in free oxygen radicals (68). Physical training represents an important source of ROS development at the level of the organs directly involved in the activity and at the level of other organs because of the supplementary energetic needs and also of the oxygen consumption (69). In agreement with the results of the present work, Liu et al.,(67) have found that acute exercise induced increases in MDA content and decrease 
glutamine synthetase activity in liver. Although regular moderate exercise training is known to increase the resistance against ROS induced lipid peroxidation, and to decrease the accumulation of oxidative proteins and DNA damage (70). However, severe exercise has been shown to induce formation of ROS and nitrogen species and the related oxidative damage (18).

In support to the results of the present work, previous studies have identified elevation in blood oxidative stress markers after severe exercise (71). A number of potential pathways exist for exerciserelated oxidant production (70), as increase oxygen consumption several folds with exercise (72), tissue damage resulting from exercise which may induce the activation of inflammatory cells such as neutrophils, with subsequent production of free radicals (73). Several studies indicate that strenuous exercise augments oxidative stress and that exercise-induced oxidative stress may damage biological components e.g. lipids and proteins (18). However, the intensity, duration and frequency of exercise are important in determining stress level and preventing or deteriorating stress response (71).

The results of the present work demonstrated that severe exercise prior to renal IR induced initiation of the apoptotic pathways as revealed by significant increase in the pro-inflammatory cytokine TNF- $\alpha$ levels and increased activity of caspase-3. Such apoptosis is probably triggered by mitochondrial permeability transition and ROS released by activated Kupffer cells (74). This leads to release of mitochondrial cytochrome $\mathrm{c}$ and activates caspase-9 which, in turn, activates caspase-3, the initiator of the final execution stages of nuclear apoptosis (75).

\section{Conclusions:}

Based on the current evidence demonstrating the key role of regular moderate physical activity in reducing and preventing the remote effects of renal IR and the associated oxidative stress in liver, moderate regular exercise may therefore prove effective as a non-pharmacological intervention in providing life-long protection against stressinduced oxidative injury and in preserving antioxidant capacity of the non-muscle tissues as liver.

\section{REFERENCES}

1. Vaghasiya JD, Sheth NR, Bhalodia YS, Jivani NP: Exaggerated liver injury induced by renal ischemia reperfusion in diabetes: effect of exenatide. Saudi J Gastroenterol. 16:174-80, 2010.

2. Emre MH, Erdogan H, Fadillioglu E: Effect of BQ-123 and nitric oxide inhibition on liver in rats after renal ischemia-reperfusion injury. Gen Physiol Biophys. 25:195-206, 2006.

3. Basireddy M, Isbell TS, Teng X, Patel RP, Agarwal A: Effects of sodium nitrite on ischemia-reperfusion injury in the rat kidney. Am J Physiol Renal Physiol. 290:F779-86, 2006.

4. Lutz J, Thürmel K, Heemann U: Antiinflammatory treatment strategies for ischemia/reperfusion injury in transplantation. $\mathrm{J}$ Inflamm (Lond). 7:27-35, 2010.

\section{Wright HL, Moots RJ, Bucknall RC,} Edwards SW: Neutrophil function in inflammation and inflammatory diseases. Rheumatology (Oxford). 49:1618-31, 2010. 
6. Erdogan H, Fadillioglu E, Yagmurca M, Ucar M, Irmak MK: Protein oxidation and lipid peroxidation after renal ischemiareperfusion injury: protective effects of erdosteine and $\mathrm{N}$-acetylcysteine. Urol Res. 34:41-6, 2006.

7. Li XL, Zou XM, Gao P, Li YL, Wang H, Chen XW: Role of nitric oxide in ischemiareperfusion injury and acute rejection in rat intestinal transplantation. Transplant Proc. 40:3342-5, 2008.

8. Golab F, Kadkhodaee M, Zahmatkesh $M$, Hedayati M, Arab H, Schuster R, Zahedi K, Lentsch AB, Soleimani M: Ischemic and nonischemic acute kidney injury cause hepatic damage. Kidney Int. 75:783-92, 2009.

9. Hoke TS, Douglas IS, Klein CL, He Z, Fang W, Thurman JM, Tao Y, Dursun B, Voelkel NF, Edelstein CL, Faubel S: Acute renal failure after bilateral nephrectomy is associated with cytokine-mediated pulmonary injury. J Am Soc Nephrol. 18:155-64, 2007.

10. Kelly KJ: Distant effects of experimental renal ischemia/reperfusion injury. $\mathrm{J}$ Am Soc Nephrol. 14:1549-58, 2003.

11. Wang B, Bai M, Bai Y, Li Q: Liver injury following renal ischemia reperfusion in rats. Transplant Proc. 42:3422-6, 2010.

12. Hotchkiss RS, Strasser A, McDunn JE, Swanson PE: Cell death. N Engl J Med. 361:1570-83, 2009.

13. Bouziana SD, Tziomalos K: Inhibition of apoptosis in the management of nonalcoholic fatty liver disease. World $\mathrm{J}$ Gastrointest Pharmacol Ther. 4:4-8, 2013.
14. Liu C, Tao Q, Sun M, Wu JZ, Yang W, Jian P, Peng J, Hu Y, Liu C, Liu P: Kupffer cells are associated with apoptosis, inflammation and fibrotic effects in hepatic fibrosis in rats. Lab Invest 90:1805-16, 2010.

15. Praphatsorn P, Thong-Ngama D, Kulaputana O, Klaikeawb N: Effects of intense exercise on biochemical and histological changes in rat liver and pancreas. Asian Biomedicine. 4:619 -25, 2010.

16. Gomez-Cabrera MC, Viña J, Ji LL: Interplay of oxidants and antioxidants during exercise: implications for muscle health. Phys Sports med. 37;116-23, 2009.

17. Katzmarzyk PT, Church TS, Janssen I, Ross R, Blair SN: Metabolic syndrome, obesity, and mortality: impact of cardiorespiratory fitness. Diabetes Care. 28:391-7, 2005.

18. Thirumalai T, Therasa SV, Elumalai EK, David E: Intense and exhaustive exercise induce oxidative stress in skeletal muscle. Asian Pacific J Tropical Disease. 1:63-6, 2011.

19. Sachdev S, Davies KJ: Production, detection, and adaptive responses to free radicals in exercise. Free Radic Biol Med. 44: 215-23, 2008.

20. Hoene M, Franken H, Fritsche L, Lehmann R, Pohl AK, Häring HU, Zell A, Schleicher ED, Weigert C: Activation of the mitogen activated protein kinase (MAPK) signaling pathway in the liver of mice is related to plasma glucose levels after acute exercise. Diabetologia. 53: 1131-41, 2010. 
21. Thiebaud RS: Exercise-Induced Muscle Damage: Is it detrimental or beneficial? J Trainol. 1:36-44, 2012.

22. Gobatto CA, de Mello MA, Sibuya CY, de Azevedo JR, dos Santos LA, Kokubun E: Maximal lactate steady state in rats submitted to swimming exercise. Comp Biochem. Physiol A Mol Integr Physiol. 130: 21-27, 2001.

23. Powers SK, Jackson MJ: Exercise-induced oxidative stress: cellular mechanisms and impact on muscle force production. Physiol Rev, 88:1243-76, 2008.

\section{Lima FD, Stamm DN, Della-Pace ID,}

Dobrachinski F, de Carvalho NR, Royes LF, Soares FA, Rocha JB, González-Gallego J, Bresciani G: Swimming training induces liver mitochondrial adaptations to oxidative stress in rats submitted to repeated exhaustive swimming bouts. PLoS One. 8:e55668, 2013.

25. Wilson DO, Johnson P: Exercise modulates antioxidant enzyme gene expression in rat myocardium and liver. J Appl Physiol. 88: 1791-6, 2000.

26. Hart KJ, Shaw JM, Vajda E, Hegsted M, Miller SC: Swim-trained rats have greater bone mass, density, strength, and dynamics. J Appl Physiol. 91:1663-8, 2001.

\section{Cunha TS, Tanno AP, Costa Sampaio}

Moura MJ, Marcondes FK: Influence of highintensity exercise training and anabolic androgenic steroid treatment on rat tissue glycogen content. Life Sci. 77: 1030-43, 2005.

28. Rei R: Measurement of aminotransferase: Part I. Asparate aminotransferase. CRC Crit Rev Clin Lab Sci. 21:99-186, 1984.
29. Esterbauer H, Cheeseman KH: Determination of aldehydic lipid peroxidation products: malonaldehyde and 4hydroxynonenal. Methods in Enzymology. 186:407-21, 1990.

30. Marklund S, Marklund G. Involvement of superoxide anion radical in the auto-oxidation of pyrogallol and convenient assay for SOD. Eur J Biochem. 47: 469-74, 1974.

31. Aebi HE: Catalase. In: Bergmeyer HU, Bergmeyer J, Grabl M, editors. Methods of enzymatic analysis. Weinheim: Velag Chemie Gmbh. 3: 273-86, 1993.

32. Nagi MN, Suneja SK, Cook L, Cinti DL: Depletion of rat hepatic glutathione and inhibition of microsomal trans-2-enoyl-CoA reductase activity following administration of a dec-2-ynol and dec-2-ynoic acid. Arch Biochem Bioophys. 293:71-8, 1992.

33. Janicke, RU, Spregart, ML, Wati MR, Porter AG: Caspase-3 is required for DNA fragmentation and morphological changes associated with apoptosis. J. Biol. Chem. 273: 9357-60, 1998.

34. Endo Y, Shibazaki M, Yamaguchi K, Kai K, Sugawara S, Takada H, Kikuchi H, Kumagai K: Enhancement by galactosamine of lipopolysaccharide (LPS)- induced tumour necrosis factor production and lethality: its suppression by LPS pretreatment. Br. J. Pharmacol. 128: 5-12, 1999.

35. Liu M, Liang Y, Chigurupati S, Lathia JD, Pletnikov M, SunZ, Crow M, Ross CA, Mattson MP, and Rabb H: Acute Kidney Injury Leads to Inflammation and Functional 
Changes in the Brain J Am Soc Nephrol. 19: 1360-70, 2008.

36. Kadkhodaee M, Golab F, Zahmatkesh M, Ghaznavi R: Effects of different periods of renal ischemia on liver as a remote organ. World J. Gastroenterol. 15: 1113-8, 2009.

37. Hurren NM, Balanos GM, Blannin AK: Is the beneficial effect of prior exercise on postprandial lipaemia partly due to redistribution of blood flow? Clin Sci (Lond). 120:537-48, 2011.

38. Gomez-Cabrera MC, Ferrando B, Brioche T, Sanchis-Gomar F, Viña J: Exercise and antioxidant supplements in the elderly. Journal of Sport and Health Science. 2: 94-100, 2013.

39. Huang CC, Tsai SC, Lin WT: Potential ergogenic effects of $\mathrm{L}$-arginine against oxidative and inflammatory stress induced by acute exercise in aging rats. Exp Gerontol. 43: 571-7, 2008.

40. Cakır B, Kasımay O, Kolgazi M, Ersoy Y, Ercan F, Yeğen BC: Stress-induced multiple organ damage in rats is ameliorated by the antioxidant and anxiolytic effects of regular exercise. Cell Biochem Funct. 28:469-79, 2010.

41. Powers SK, Jackson MJ: Exercise-induced oxidative stress: cellular mechanisms and impact on muscle force production. Physiol Rev. 88:1243-76, 2008.

\section{Kalani R, Judge S, Carter C, Pahor M,}

Leeuwenburgh C: Effects of caloric restriction and exercise on age-related, chronic inflammation assessed by CRP and interleukin6. J Gerontol A Biol Sci Med Sci. 61: 211-7, 2006.
43. Navarro A, Gomez C, Lopez-Cepero JM, Boveris A: Beneficial effects of moderate exercise on mice aging: survival, behavior, oxidative stress, and mitochondrial electron transfer. Am J Physiol Regul Integr Comp Physiol 286: R505-11, 2004.

44. Marques PE, Amaral SS, Pires DA, Nogueira LL, Soriani FM, Lima BH, Lopes GA, Russo $\quad$ RC, Avila TV, Melgaço JG, Oliveira AG, Pinto MA, Lima CX, De Paula AM, Cara DC, Leite MF, Teixeira MM, Menezes GB: Chemokines and mitochondrial products activate neutrophils to amplify organ injury during mouse acute liver failure. Hepatology. 56:1971-82, 2012.

45. Park SW, Chen SW, Kim M, Brown KM, Kolls JK, D'Agati VD, Lee HT: Cytokines induce small intestine and liver injury after renal ischemia or nephrectomy. Laboratory Investigation. 91:63-84, 2011.

46. Park SW, Kim M, Brown KM, D'Agati VD, Lee HT: Paneth cell-derived interleukin-17A causes multiorgan dysfunction after hepatic ischemia and reperfusion injury. Hepatology. 53: 1662-75, 2011.

47. Helk E, Bernin H, Ernst T, Ittrich H, Jacobs T, Heeren J, Tacke F, Tannich E, Lotter $\mathbf{H}$ : $\mathrm{TNF} \alpha$-mediated liver destruction by Kupffer cells and Ly6Chi monocytes during Entamoeba histolytica infection. PLoS Pathog. 9:e1003096, 2013.

48. Serteser M, Koken T, Kahraman A, Yilmaz K, Akbulut G, Dilek ON: Changes in hepatic TNF-alpha levels, antioxidant status, and oxidation products after renal 
ischemia/reperfusion injury in mice. J Surg Res. 107:234-40, 2002.

49. Yildirim A, Gumus M, Dalga S, Sahin YN, Akcay F: Dehydroepiandrosterone improves hepatic antioxidant systems after renal ischemia-reperfusion injury in rabbits. Ann. Clin. Lab. Sci. 33: 459-64, 2003.

50. Ji LL, Gomez-Cabrera MC, Vina J: Exercise and hormesis: activation of cellular antioxidant signaling pathway. Ann NY Acad Sci. 1067:425-35, 2006.

\section{Radák Z, Chung HY, Goto S: Opinion:}

Exercise and hormesis: oxidative stress-related adaptation for successful aging. Biogerontology. 6:71-5, 2005.

52. Packer L, Cadenas E: Oxidants and antioxidants revisited. New concepts of oxidative stress. Free Radic Res. 41: 951-2, 2007.

\section{Sun L, Shen W, Liu Z, Guan S, Liu J, Ding}

S: Endurance exercise causes mitochondrial and oxidative stress in rat liver: effects of a combination of mitochondrial targeting nutrients. Life Sci. 86: 39-44, 2010.

\section{Nikolaidis MG, Jamurtas AZ, Paschalis V,} Fatouros IG, Koutedakis Y, Kouretas D: The effect of muscle-damaging exercise on blood and skeletal muscle oxidative stress: magnitude and time-course considerations. Sports Med. 38:579-606, 2008.

\section{Botezelli JD, Cambri LT, Ghezzi AC, Dalia} RA, M Scariot PP, Ribeiro C, Voltarelli FA, Mello MA: Different exercise protocols improve metabolic syndrome markers, tissue triglycerides content and antioxidant status in rats. Diabetol Metab Syndr. 3:35-42, 2011.

56. Radák Z, Chung HY, Naito H, Takahashi R, Jung KJ, Kim HJ, Goto S: Age-associated increase in oxidative stress and nuclear transcription factor NF- $\mathrm{BB}$ activation are attenuated in rat liver by regular exercise. FASEB J. 18:749-50, 2004.

57. Goto S, Radák Z: Regular exercise attenuates oxidative stress in aging rat tissues: a possible mechanism toward anti-aging medicine. J Exerc Sci Fit. 5:1-6, 2007.

58. Kakarla P, Vadluri G, Reddy Kesireddy S: Response of hepatic antioxidant system to exercise training in aging female rat. J Exp Zool A: Comp Exp Biol. 303:203-8, 2005.

59. Elahi MM, Matata BM: Free radicals in blood: evolving concepts in the mechanism of ischemic heart disease. Arch Biochem Biophys. 450:78-88, 2006.

60. Wright E Jr, Scism-Bacon JL, Glass LC: Oxidative stress in type 2 diabetes: the role of fasting and postprandial glycaemia. Int $\mathrm{J}$ Clin Pract. 60:308-14, 2006.

61. Korolainen MA, Goldsteins G, Nyman TA, Alafuzoff I, Koistinaho J, Pirttilä T: Oxidative modification of proteins in the frontal cortex of Alzheimer's disease brain. Neurobiol Aging. 27:42-53, 2006.

62. Shanely R.A, Nieman DC, Henson DA, Jin F, Knab AM, Sha W: "Inflammation and oxidative stress are lower in physically fit and active adults," Scandinavian Journal of 
Medicine and Science in Sports. 23: 215-23, 2011.

\section{Christiansen T, Paulsen SK, Bruun JM,}

Pedersen SB, Richelsen B: Exercise training versus diet-induced weight-loss on metabolic risk factors and inflammatory markers in obese subjects: a 12-week randomized intervention study. Am J Physiol Endocrinol Metab. 298:E824-31, 2010.

\section{Gleeson M, Bishop NC, Stensel DJ, Lindley} MR, Mastana SS, Nimmo MA: The antiinflammatory effects of exercise: mechanisms and implications for the prevention and treatment of disease. Nat Rev Immunol. 11:607-15, 2011.

65. Abramson JL, Vaccarino V: Relationship between physical activity and inflammation among apparently healthy middle-aged and older US adults. Arch Intern Med. 162:128692, 2002.

66. Smith MA, Reid MB: Redox modulation of contractile function in respiratory and limb skeletal muscle. Respir Physiol Neurobiol. 151:229-41, 2006.

67. Liu J, Helen CY, Eva O, Vervik-Douki, Tory H, Stephanie JD, Daniel WC, George AB, Bruce NA: Chronically and acutely exercised rats: biomarkers of oxidative stress and endogenous antioxidants. J. App. Physiol. 89: 21-8, 2000.

68. Marius-Daniel R, Dragomir C, Stelian S: The effect of acute physical exercise on liver and kidney in the Wistar rat. Romanian Biotechnological Letters. 15:51-5, 2010.
69. Cooper CE, Vollaard NBJ, Choueiri T, Wilson MT: Exercise, free radicals and oxidative stress. Biochem. Soc. Trans. 30: 280$5,2002$.

70. Belviranli M, Gökbel H: Acute exercise induced oxidative stress and antioxidant changes. Eur J Gen Med. 3: 126-31, 2006.

71. Takahashi M, Suzuki K, Matoba H, Sakamoto S, Obara S: Effects of different intensities of endurance exercise on oxidative stress and antioxidant capacity. J Phys Fitness Sports Med. 1: 183-9, 2012.

72. Fisher-Wellman K, Bloomer RJ: Acute exercise and oxidative stress: a 30 year history. Dyn Med 13: 1-25, 2009.

73. Quindry JC, Stone WL, King J, Broeder CE: The effects of acute exercise on neutrophils and plasma oxidative stress. Med Sci Sports Exerc 2003; 35:1139-45.

74. Zhang L, Li HZ, Gong X, Luo FL, Wang B, Hu N, Wang CD, Zhang Z, Wan JY: Protective effects of Asiaticoside on acute liver injury induced by lipopolysaccharide /Dgalactosamine in mice. Phytomedicine. 17:8119, 2010 .

75. Meki AR, Esmail Eel-D, Hussein AA, Hassanein HM: Caspase-3 and heat shock protein-70 in rat liver treated with aflatoxin $\mathrm{B} 1$ : effect of melatonin. Toxicon. 43:93-100, 2004. 


\section{الملخص العربي}

هاف هذا البحث : هو معرفة تأثير الممارسة المتوسطة والعنيفة لرياضة السباحة على إصابة الكبد الناتجة من نقص و إعادة التروية بالكلى فى ذكور الفئر ان البيضاء

طرق البحث: تم إجر اء البحث على 40من ذكور الفئران البيضـاء وقد تم تقسيمهم إلى أربع مجموعات تتكون كل مجمو عة من إن

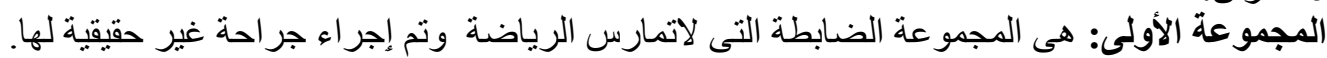

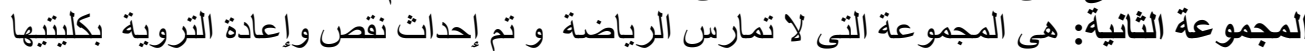

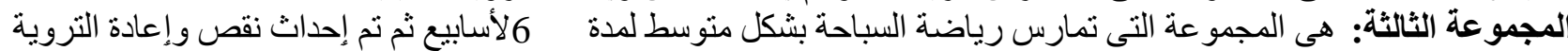

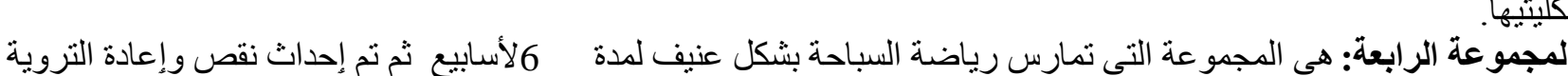

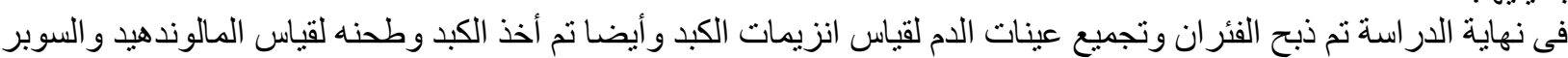

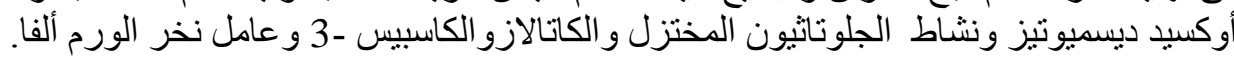

نتائج البحث: فى المجموعة التى تم اجر اء لها عملية نقص و إعادة التروية بكليتيها وجد زيادة في مستوب إنزيمات الكبات الكبد وكانت هذه

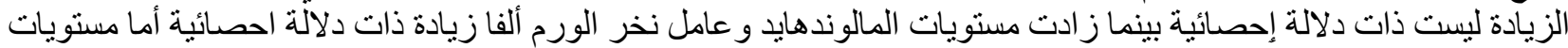

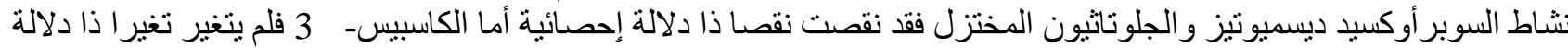
احصائية إذا قورن بالمجمو عة الضابطة.

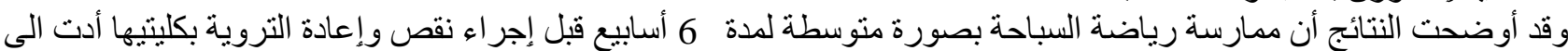

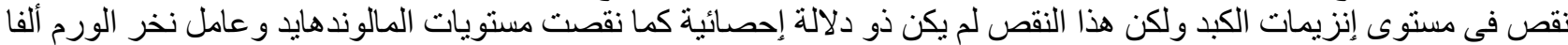

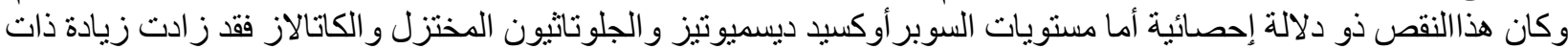

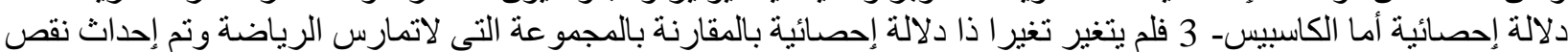
وإعادة التروية بكليتيها.

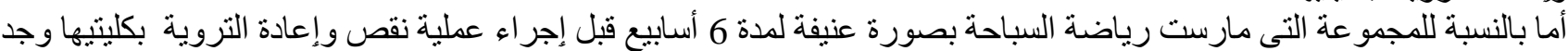

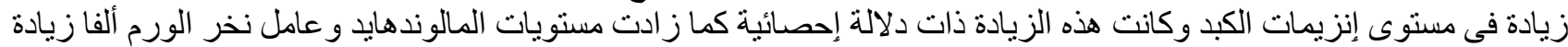

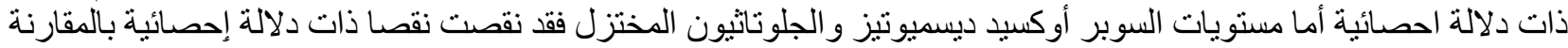

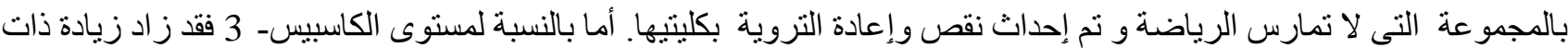

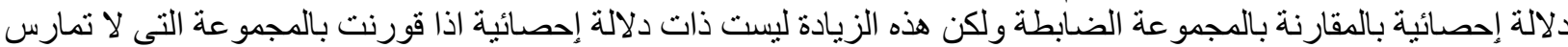

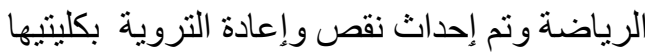

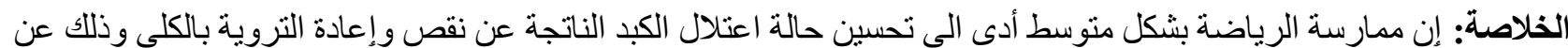

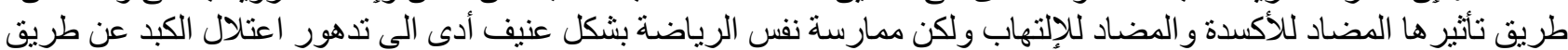
زيادة الأكسدة. 